\author{
Assistant Professor Maria Claudia DIACONEASA, PhD \\ The Bucharest University of Economic Studies \\ E-mail: mariaclaudiadiaconeasa@gmail.com \\ Professor Gabriel POPESCU, PhD \\ The Bucharest University of Economic Studies \\ E-mail: popescug2004@yahoo.co.uk \\ Professor Dan BOBOC, PhD \\ The Bucharest University of Economic Studies, \\ E-mail: dan.boboc@eam.ase.ro
}

\title{
SUSTAINABLE FOOD CONSUMPTION IN THE WEB OF SCIENCE ABSTRACTS
}

\begin{abstract}
The sustainable food consumption topic is a comprehensive one, including under its research area several perspectives, from the individual ones considering health benefits, income restrictions or educational factors, to collective perspectives - considering availability of sustainable food, marketing strategies or even national and international policies in favour of sustainable food consumption.

In this case, it is obvious that research does not stand on the sole ground of consuming ecological products, but it has many more anchors and strings, so it should be a topic of interest for many researchers. In this case, this paper presents a bibliometric analysis of the sustainable food consumption topic as it appears in all the abstracts on Web of Science data base and a word network mapping of the main themes and sub-themes mostly used by the researchers in this area of knowledge, with the help of the Vosviewer software.
\end{abstract}

Key words: Sustainable food consumption; trends; word network mapping.

\section{JEL Classification: Q01, Q18}

\section{Introduction}

Sustainability represents a very resourceful topic considering its applicability, as a concept, on every other area of interest, either regarding new industries or DOI: $10.24818 / 18423264 / 53.1 .19 .19$ 
approaches on old ones, or what any individual may do to reduce its negative impact on the environment.

A particular interest is generated by the sustainable food consumption, as it comes with changes on a basic human need, that of eating. Moreover, this concept exceeds the boundaries of the basic human need and it includes human behavioural changes, factors that determine the change, differences between genders, incomes or geographical areas. While food consumption may be a simple fact, it implies many choices based on a quantity of information that grows every day, either if we consider the agricultural process used to obtain the primary resources, the industries used to transform those resources into food and their impact on both human health and the environment.

In this case, the present paper aims at assessing all the article abstracts on the topic of sustainable food consumption available on Web of Science data base in order to elicit the researchers' interest in this topic and to capture the issues that are the most debated.

The paper should be of interest to researchers as it offers a summary of the sustainable food consumption topic, as well as to resort authorities and other stakeholders, who should be constantly updated on the developments in this area. As methodological pointers, two methods were used in this analysis. For determining the researchers' interest in the topic, the bibliometric indicators were extracted and synthetized, while for creating the word network map, in order to see the most important themes of this topic, the Vosviewer software, version 1.6.7 was used (Van Eck and Waltman, 2014).

\section{Literature review}

While authors like Kearney (2010) observe major shifts the in dietary patterns worldwide, such as the high number of obese people or the preference of vegetarian diets, and call out the need for developing coherent and sustainable practices that would benefit human health, agriculture and the environment, other authors (Tanner and Wölfing Kast, 2003) analysed the factors that might trigger a more sustainable consumption attitude in humans. Their results point out that factors like environmental protection, fair trade, local products, and availability of action-related knowledge have a positive influence on green purchases, while factors such as perceived time barriers and frequency of shopping in supermarkets have a negative influence. Even more, moral thinking, monetary barriers and socioeconomic characteristics of the analysed consumers were not significantly related to green purchases, as the study demonstrates. 
Sustainable Food Consumption in the Web of Science Abstracts

In addition, Seyfang (2006) finds that ecological citizenship might act as a powerful motivation in favour of sustainable consumption behaviour. In this case, one might conclude that even if, at a moral level, sustainable consumption is the correct way, the reality proves that some incentives, physical or psychological, are needed to power up the transition to this type of consumption in most of the population.

Even more, Vermeir and Verbeke (2006) demonstrate in their study that there is a gap between attitudes and behaviour. While most of their interviewees have a positive attitude towards sustainable food consumption, there are factors like impact of involvement, perceived availability, certainty or perceived consumer effectiveness that influence which influence their purchase behaviour. This study confirms the idea that the transition to a new consumption model needs social recognition in order to be desirable.

Young et all. (2010) claim that there is a barrier regarding the purchase of green or ethical foods, $30 \%$ of the UK consumers report that they would like to buy this kind of foods, but they are struggling to put that into practice due to the high amount of time needed to choose between products. In this case, a more suggestive labelling system is recommended by the authors. Dabija and Bejan (2017) analyse the differences between generations and claim that the youth is more inclined towards sustainable foods than their elders, so differentiated market strategies have started to surface.

Shifting from the individual perspective approached in the previous mentioned studies, to a macroeconomic perspective proposed by Godfray et all. (2010), the acceptance of sustainable food consumption is part of a global strategy that should enable us to feed unprecedent growing population.

Other authors address the problem of food loss, as part of a sustainable consumption (Wunderlich and Martinez, 2018), claiming that the current consumption pattern is far from sustainable, 1.3 billion tons of food being wasted each year.

Regarding food waste reduction, authors like Lagorio, Pinto and Golini (2018) and Derqui, Fernandez and Fayos (2018) present case studies on school canteens - as big food waste generators, and they point out that this initiatives have several benefits, first by involving different stakeholders, the waste can be significantly reduced, and also, an educative benefit, due to the closeness to schools.

\section{Short bibliometric analysis on the sustainable food consumption}

This short bibliometric analysis investigates the publications on Web of Science (WoS), which contains the syntax "sustainable food consumption" in the 1975- 
2018 time frame. There are 103 publications, of which were registered more than 10 publications yearly only since 2013 . So, the focus on this subject is of relatively new interest. In 1998, it was published the first paper and the only one which contains "sustainable food consumption" in the title, the abstract or the content of the paper while in 2018 were published 22 documents on this topic. 84 publications were articles, 10 proceedings papers, and nine other types of documents, such as reviews and book chapters. The main WoS fields of these studies are environmental research, food science technology, green sustainable science technology, nutrition dietetics, economics, business, and other 16 more. However, the main research fields of these studies are business economics, environmental sciences ecology, food science technology, nutrition dietetics, agriculture, and other 19 more. 26 of all 103 papers received a funding grant.

The authors with more than three publications on this topic are Verbeke W. (5), Saba A. (3), Scalvedi ML (3), Temme EHM (3), and Verkaik-Kloosterman J (3), of 279 authors in total. However, the most cited authors are Vermeir I. and Verbeke W. with a 2006 paper cited 519 times and a 2008 study cited 197 times. On the third place, Carlsson-Kanyama A. was cited 145 times on the relation between climate change and dietary choices since 1998.

Table 1 presents the most cited authors and their papers' information with more than 61 citations.

Table 1 Most cited authors and their papers on "sustainable food consumption"

\begin{tabular}{c|c|c}
\multicolumn{2}{|c}{ consumption" } \\
\hline Authors & Title & Year \\
\hline Vermeir, I; & $\begin{array}{c}\text { Sustainable food consumption: Exploring the consumer } \\
\text { Verbeke, W }\end{array}$ & 2006 \\
\hline $\begin{array}{c}\text { Vermeir, Iris; } \\
\text { Verbeke, } \\
\text { Wim }\end{array}$ & $\begin{array}{c}\text { Sustainable food consumption among young adults in } \\
\text { Belgium: Theory of planned behaviour and the role of } \\
\text { confidence and values }\end{array}$ & 2008 \\
\hline $\begin{array}{c}\text { Carlsson- } \\
\text { Kanyama, A }\end{array}$ & $\begin{array}{c}\text { Climate change and dietary choices - how can } \\
\text { emissions of greenhouse gases from food consumption } \\
\text { be reduced? }\end{array}$ & 1998 \\
\hline $\begin{array}{c}\text { Verain, } \\
\text { Muriel C. D.; } \\
\text { Bartels, Jos; } \\
\text { Dagevos, } \\
\text { Hans; et al. }\end{array}$ & Segments of sustainable food consumers: a literature \\
review & 2012 \\
\hline Pieniak, & Subjective and objective knowledge as determinants of & 2010 \\
\hline
\end{tabular}


Sustainable Food Consumption in the Web of Science Abstracts

\begin{tabular}{c|c|c}
\hline Zuzanna; & organic vegetables consumption & \\
Aertsens, & & \\
Joris; & & \\
Verbeke, & & \\
Wim & & \\
\hline
\end{tabular}

Source: own presentation based on WoS, 2018

The studies are affiliated mostly with Germany, Italy, Netherlands, Belgium, USA, France, and Sweden, while the main language was English for 100 papers and the remaining three were published in French, German and Hungarian languages.

\section{Main concepts used in sustainable food consumption articles on Web of}

\section{Science}

Regarding the main themes and sub-themes that appear in the titles and abstracts of the 103 publications from the Web of Science Science data base, in the economics section when searching for the "sustainable food consumption" key phrase, they are elicited by using Vosviewer, version 1.6.7., a software which uses word frequency and co-occurrence in order to generate word network maps (Van Eck and Waltman, 2014).

From the 103 publications extracted from the data base, the total number of terms is 2817 , out of these terms, a very high importance have those which appear at least 10 times in the corpus, in this case there are 60 terms which meet the condition. The most important terms in the corpus are those which appear at least 20 times in the corpus, in this case there are only 15 terms which meet the condition, and they are presented in Table 2 and ordered by the automatically calculated relevance score.

Table 2 Most important terms in the "sustainable food consumption corpus"

\begin{tabular}{|c|c|c|c|}
\hline Term & Occurrence & Term & Occurrence \\
\hline Meat consumption & 22 & Information & 40 \\
\hline Meat & 39 & Study & 97 \\
\hline Intention & 50 & $\begin{array}{c}\text { Food } \\
\text { consumption }\end{array}$ & 39 \\
\hline Food & 128 & Sustainability & 40 \\
\hline Consumer & 145 & Behaviour & 38 \\
\hline Product & 96 & $\begin{array}{c}\text { Sustainable food } \\
\text { consumption }\end{array}$ & 76 \\
\hline Attitude & 51 & Paper & 48 \\
\hline Consumption & 100 & & \\
\hline
\end{tabular}

Source: own calculation with the Vosviewer 1.6.7 software 
The focal point of discussion in the sustainable food consumption topic remains the consumer, with 145 appearances in the selected corpus. It is followed naturally by the term food, with 128 appearances and consumption with 100 appearances, these being the terms with the highest frequency. There needs to be mentioned that the phrase "food consumption" also appears 39 times in the corpus, while "sustainable food consumption" has a 76 appearance frequency. Other words that raise awareness come from a different category, that of research, and they are: intention, attitude, behaviour, information, study, paper and sustainability. The connections between words may be seen in Figure 1.

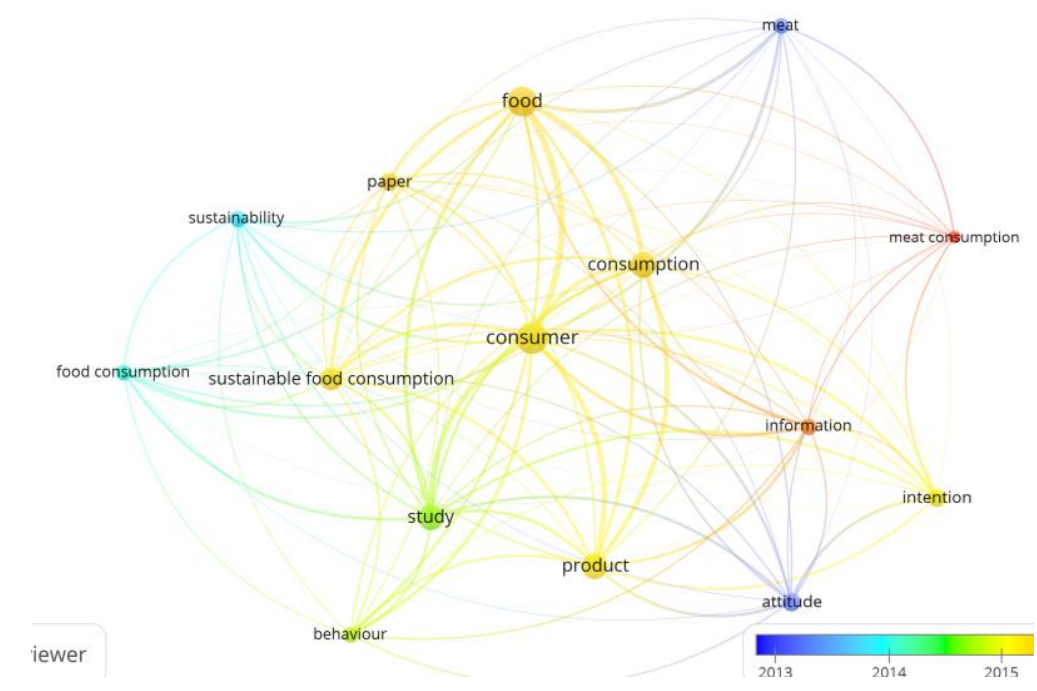

Figure 1. Network map of the most important 15 terms

The connections between the words show a diverse interest in researching areas of this topic, but most of them circle around the individual, the consumer and its activity, the consumption. Attitude and intention are strongly connected, and both appear next to meet consumption, which seems to be the latest interest point.

Words like study, information, food and sustainability stand as bridges between the other terms on the map, having multiple connections with almost every other term. An aspect that needs to be mentioned is that no negative term can be found in the list of the most important, so terms like food waste, reduction or concern, which one would expect to find in this type of research, cannot be found here. In this 
case, the map of terms with an occurrence higher than 10 has been generated and can be seen in Figure 2.

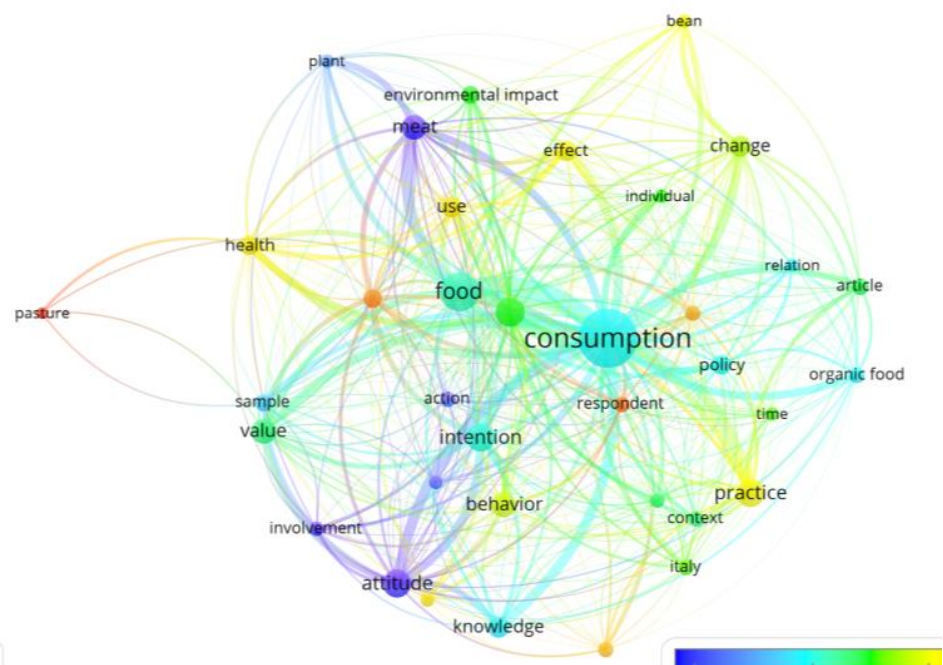

Figure 2. Network map of the most important 60 terms

In the list of the terms that occur more than 10 times in the corpus, there are several which suggest the need to change the current consumption pattern, such as: involvement (13), change (28), health (25), knowledge (30), way (14) or attention (12). Other have the intention of raising a red flag, such as: climate change (12), environmental impact (20) or effect (27). Also, there are terms which suggest problems of the consumers regarding sustainable products, such as: time (12) or value (38), referring to the fact that these products are more expensive, and it is time consuming to identify them on the shelf. What is more important is that the individual (12) or respondent (16) and the household (16) are taken into consideration as well as the policy (24), context (16) or Italy (15), which means that both the micro and macro levels are considered in the research on the topic of sustainable food consumption. Also, terms that suggest solutions to the current consumption pattern are key points on the map, such as: organic food (16) or diet (53).

As a remark, there should be more interest regarding the national governments' actions and legislative plans regarding possible development and favouring the sustainable food consumption practice. 
Maria Claudia Diaconeasa, Gabriel Popescu, Dan Boboc

\section{Conclusions}

The debated topic is at the beginning of its time, a small number of articles have been found on the Web of Science data base, only 103. However, the interest proved by publication number and the debated themes and sub-themes has grown since 2013. The consumer and its consumption pattern stand in the centre of the researchers' interest, these being the most frequent terms found in the corpus.

The areas of interest spread between the micro level which consider the individual or the household and what a new consumption pattern mean to it in terms of availability, value or behaviour and the macro level of policies regarding sustainable consumption or the environmental impact of the current consumption pattern.

The current involvement of national authorities in promoting or regulating sustainable food consumption have not raised enough interest from the researchers' side, this may be because currently there is very little activity in this area from the authorities' part, with Italy's exception, as it results from the analysis.

Some limitations may come from the option of only analysing the article abstracts, while the extended papers may offer different results. In this case, in a future research, the extended papers will be considered.

\section{REFERENCES}

[1]Dabija, D. C. \& Bejan, B. M. (2017), A Cross-Generational Perspective on Green Loyalty in Romanian Retail. In Griffiths School of Management and IT Annual Conference on Business, Entrepreneurship and Ethics (pp. 1-23). Springer, Cham;

[2]Derqui, B., Fernandez, V. \& Fayos, T. (2018), Towards more Sustainable Food Systems. Addressing food waste at school canteens. Appetite;

[3]Godfray, H. C. J., Beddington, J. R., Crute, I. R., Haddad, L., Lawrence, D., Muir, J. F.\& Toulmin, C. (2010), Food Security: The Challenge of Feeding 9 Billion People. Science, 1185383;

[4]Kearney, J. (2010), Food Consumption Trends and Drivers. Philosophical Transactions of the Royal Society of London B: Biological Sciences, 365(1554), 2793-2807;

[5]Lagorio, A., Pinto, R. \& Golini, R. (2018), Food Waste Reduction in School Canteens: Evidence from an Italian Case. Journal of Cleaner Production, 199, 7784 
Sustainable Food Consumption in the Web of Science Abstracts

[6]Seyfang, G. (2006), Ecological Citizenship and Sustainable Consumption: Examining Local Organic Food Networks. Journal of rural studies, 22(4), 383395;

[7]Tanner, C. \& Wölfing Kast, S. (2003), Promoting Sustainable Consumption: Determinants of Green Purchases by Swiss Consumers. Psychology \& Marketing, 20(10), 883-902;

[8]Van Eck, N.J. \& Waltman, L. (2014), Visualizing Bibliometric Networks. In $Y$. Ding, R. Rousseau \& D. Wolfram (Eds.), Measuring scholarly impact: Methods and practice (pp. 285-320). Springer;

[9] Vermeir, I. \& Verbeke, W. (2006), Sustainable Food Consumption: Exploring the Consumer "Attitude-Behavioral Intention" Gap. Journal of Agricultural and Environmental Ethics, 19(2), 169-194;

[10]Wunderlich, S. M. \& Martinez, N. M. (2018), Conserving Natural Resources Through Food Loss Reduction: Production \& Consumption Stages of the Food Supply Chain. International Soil and Water Conservation Research; [11] Young, W., Hwang, K., McDonald, S. \& Oates, C. J. (2010), Sustainable Consumption: Green Consumer Behaviour when Purchasing Products.

Sustainable Development, 18(1), 20-31. 